through this canal with a small hand syringe, thus facilitating its introduction.

I was led to feel the need of such an instrument by having to attend a man over 70 years old, who, after months of catheter life from enlarged prostate, was operated on by Dr. J. B. Murphy. After some months the patient again had trouble in fully evacuating the bladder. Dr. Murphy advised me to introduce a sound once a week, or two weeks as required. This maintained the patency of the canal, but did not drain off the residual urine. 'This necessitated the use of a catheter afterward. The sound would frequently pass into the bladder when neither a soft nor metallic catheter would do so, unless the sound preceded it.

The bladder can also be readily washed out by attaching a fountain syringe to the hollow projecting point $B$ in the engraving.

\section{MARKED MALPOSITION OF THE SIGMOID SINUS.}

\section{RICHARD H. JOHNSTON, M.D.} BALTIMORE.

On March 16 of the present year I was called on to open the mastoid of Fulton M., aged 5 , who had suffered from acute suppurative otitis media for two weeks. There was decided swelling of the skin over the bone. After making the usual incision through the skin, a small fistula was found in the mastoid fossa which passed down through the cortex. After removing the bone, granulation tissue was encountered, but the peculiar doughy sensation imparted to the probe warned against the use of the curette. The soft tissue was carefully uncovered from the mastoid fossa to the tip, and everywhere presented the same granular appearance. Its position was directly back of the posterior wall of the canal. There was no pulsation of the mass. In trying to make a positive diagnosis a portion of the canal wall was removed and even then it was impossible to tell whether I was dealing with granulation tissue alone or with the sinus covered by it.

At one point the granulations were accidentally scraped off and a bluish shimmer convinced me that I was dealing with the sinus. To make assurance doubly sure a sterile, hypodermic needle was pushed through the blue spot and the withdrawal of dark blood made the diagnosis positive. The position of the sinus was directly back of the posterior wall of the canal, hugging it as closely as possible, and extending from the mastoid fossa just below the dura above to the uncovered tip below. Its direction was perfectly straight instead of the usual $S$ shape. The position of the vessel changed an apparently simple operation into a complicated one. Since there was no evidence of thrombosis, the granulation tissue was not disturbed. The skin wound was sutured a short distance above and left open below.

The patient made an uneventful recovery. I had never seen such a marked displacement of the sinus.

919 North Charles Street.

\section{TETANUS TREATED WITH MAGNESIUM SUL- PHATE BY HYPODERMOCLYSIS.}

\section{MORTON LYON, M.D.} DE WITT, IOWA.

I wish to report a case of tetanus treated with magnesium sulphate by hypodermoclysis, with recovery:

The patient, J. K., male, 7 years old, stepped on a nail, which punctured the sole of his shoe and entered the left foot, barely through the skin, making a wound scarcely noticeable.

Eight days later he complained of stiffness in his foot and leg. On the ninth day a spasm of the leg caused him to fall, and rigidity of muscles was increased. On the tenth day trismüs was noticed and there were occasional convulsions. On the eleventh day I was called to see him and found his jaws set and almost all his muscles rigid. He could move his arms and hands to a limited extent. The wound was laid open and thoroughly treated with hydrogen dioxid and tincture of iodin.

The convulsions were partially controlled by morphin, chloral and bromids. On the twelfth day, at $3 \mathrm{p.} \mathrm{m}$., I gave two drams magnesium sulphate in four ounces of distilled water under the skin of abdomen. At the end of two hours the boy could separate teeth $2 \mathrm{~cm}$., and his other muscles were relaxed to a marked degree. On the thirteenth, fourteenth, seventeenth and nineteenth days the magnesium sulphate injection was repeated, and, although the muscles were not relaxed to the same extent as after the first injection, the convulsions were infrequent and not so severe. Only twice was there any bronchorrhea, and then of slight consequence. About the fourteenth day a vesicular eruption appeared all over his body. The vesicles were of pin-head size and filled with a clear fluid. These dried up and disappeared with an exfoliation of epidermis in about one week.

From the last injection of magnesium sulphate on the nineteenth day the stiffness in muscles slowly disappeared, the last to disappear being in the foot which was injured. It was necessary to give digitalis to improve heart action after the first week of illness, and tonics for anemia during convalescence. About the thirtieth day he was able to sit up, and in ten days more to walk again as usual.

\section{CASE OF MULTIPLE SACCULATED THORACIC ANEURISM SUCCESSFULLY TREATED BY WIRING.}

\author{
JAMES M. ANDERS, M.D., LL.D. \\ AND \\ JAMES P. MANN, M.S., M.D. \\ PHILADELPHIA.
}

Patient.-M. W., a colored man, aged 36 years, was admitted to the Medico-Chirurgical Hospital, Jan. 18, 1907, complaining of a painful, throbbing Iump in the sternal region, a troublesome cough, marked dyspnea, and general weakness.

History.-The family history was negative. The patient as a child had measles and mumps. When about ten years of age he fell and sustained an injury to the chest, to which accident he attributed his present condition, though the first local symptoms appeared twenty years later. He had always been more or less subject to colds and had suffered from several slight attacks of acute rheumatism. For the past twelve years he had been a barber and had previously been employed for a number of years on a farm. He had used tea and coffee in moderation, but tobacco, beer and whisky freely until entering the hospital. He had been married eight years. The patient admitted a specific infection, the primary lesion appearing, however, only four months previous to the time of his admission.

The present illness began about four years ago, when he noticed a dull boring pain under the sternum. Soon, a small, painful, throbbing protuberance appeared to the right of the mid-sternal region, but this swelling largely disappeared un. der absolute rest and medicinal measures. During the four years intervening between that date and his admission to the hospital, he had an occasional pain in the same region, and a cough at intervals, which, however, was not characteristic of thoracic aneurism.

Since Christmas, 1906, he had a severe cough, which caused considerable pain in the area of the original swelling. On January 14, four days prior to date of admission, be indulged in a "spree," during which he suddenly felt a sharp pain accompanied by a sense of "something giving way" in the chest. This was attended with a smothering sensation, and at the same time he noticed a return of the swelling. The tumor now rapidly enlarged and four days later it was about the size of a small orange. Neither dysphagia nod aphonia was present.

Examination.-On admission to the hospital, the most striking feature of the physical examination was a conical tumor. 